\title{
WASYLISA PREKRASNAJA I INNI \\ W ROSYJSKIEJ LUDOWEJ BAJCE MAGICZNEJ
}

\author{
VASILISA PREKRASNAYA AND OTHERS \\ IN A RUSSIAN FOLK FAIRYTALE
}

\section{MAŁGORZATA WIATR-KMIECIAK, HALINA WIATR}

\begin{abstract}
The aim of this paper is to emphasize the importance of Russian folk literature in the form of a fairytale and to show potential difficulties in translation. Folk literature cannot be seen only as a certain form of ordinary people's artistic voice since it has been developing in parallel with the mainstream literature in Russia. Russian folk fairytale has a specific structure and form which does not exist in any other culture. Like in many other languages and cultures, there are certain names, descriptive adjectives and other forms that are very challenging for translators. In this paper many examples are provided to support this hypothesis. It is almost impossible to translate certain Russian fairytales without "over-" or "under-interpreting" the content, and the subject matter itself needs to be thoroughly elaborated.
\end{abstract}

Małgorzata Wiatr-Kmieciak, Uniwersytet im. Adama Mickiewicza w Poznaniu, Halina Wiatr, emerytowany pracownik Uniwersytetu im. Adama Mickiewicza w Poznaniu, Poznań - Polska.

Przedmiotem rozważań niniejszej wypowiedzi będzie znaczenie kulturoznawcze ludowej rosyjskiej bajki magicznej i możliwości translacyjne przekazu wartości realioznawczych w przekładach polskich.

Rozważania nasze rozpoczniemy od określenia terminu "folklor” oraz jego zakresu znaczeniowego. Otóż, jak stwierdza Ryszard Łużny, „poezja ludowa”, "ludowa literatura" lub "ludowa tradycja”, "twórczość poetycka ludu" - to najczęstsze, przyjęte w nauce od XIX wieku, terminy na oznaczenie kręgu specyficznych przejawów samorodnej i spontanicznej twórczości słownej mas ludowych, która kształtowała się niezależnie od tzw. literatury uczonej, oficjalnej. Literatura ludowa najczęściej wyprzedzała powstanie właściwego piśmiennictwa i rozwijała się zgodnie z własnymi prawidłowościami równolegle $\mathrm{z}$ nim, a nawet, chociaż długo niedoceniana i niekiedy tępiona, oddziaływała na kulturę literacką, wchodząc z nią w rozliczne koneksje, służąc jej jako rezerwuar treści i środków artystycznych, cech i osobliwości o specyficznym obliczu narodowym ${ }^{1}$.

\footnotetext{
${ }^{1}$ R. Ł u ż n y, Rosyjska literatura ludowa, Warszawa 1977, s. 9.
} 
Termin "folklor", wprowadzony w 1846 roku przez angielskiego badacza W. Thomsona, jest znaczeniowo szerszy (mądrość, wiedza ludu) i może oznaczać nie tylko tę "gminną poezję" - popularną masową literaturę, ale także cały kompleks materialnej i duchowej kultury tworzonej przez lud².

Za ludowe uważamy takie utwory, które powstały w wyniku twórczych wysiłków zbiorowości, a więc mające charakter kolektywny oraz anonimowy. Będąc wyrazem wspólnej ludowej mądrości, mówią one o pewnym kręgu zjawisk w sposób dla ludowego twórcy właściwy, a dla określonego odbiorcy dostępny. Równocześnie, zgodnie z ogólnymi zasadami sztuki słowa, twórcy folkloru korzystają z różnych kategorii estetycznych, konwencji rodzajowo-gatunkowych i stylistycznych środków obrazowo-artystycznych. W folklorze rosyjskim znajdujemy wszystkie trzy podstawowe typy rodzajowe: epikę, lirykę i dramat, a także wiele form pośrednich, a więc przysłów, zagadek, zaklęć, porzekadeł itp.

Najbardziej rozbudowane i zróżnicowane są dwie dziedziny: epika i liryka. W nich ludowy twórca zbiorowy wypowiedział się najpełniej i najbardziej wszechstronnie. W bylinie, pieśni historycznej, a przede wszystkim w bogatym eposie baśniowym, przedstawił swój sposób widzenia otaczającej go rzeczywistości - człowieka, przyrody, świata materialnego i ponadnaturalnego ${ }^{3}$.

W obrębie epiki baśniowej poczesne miejsce zajmuje ludowa bajka magiczna, a ponieważ znalazła się ona w kręgu naszych zainteresowań, należy odpowiedzieć na pytanie, czym jest bajka magiczna i jakie są jej główne wyznaczniki formalne.

Do konkretyzacji samego pojęcia bajki magicznej i nadania koncepcji gatunku cech systemowości znacząco przyczyniły się formalne badania radzieckiego folklorysty W.J. Proppa ${ }^{4}$. W oparciu (m.in.) o te badania J. Ługowska ${ }^{5}$ sformułowała następującą definicję:

Ludowa bajka magiczna jest to gatunek, w którym:

1) nadrzędną zasadą semiotycznej organizacji tematu jest konstruowanie wizji rzeczywistości intencjonalnej, odpowiadającej marzeniom człowieka, w której w sposób bezwyjątkowy i wzorcowy działają prawa zgodne z ludowym poczuciem sprawiedliwości i moralnego ładu świata;

2) fabuła opiera się na podstawowym schemacie, którego immanentna logika wiedzie od „szkody” lub „braku” (określenia Proppa) do ostatecznego sukcesu bohatera osiągniętego przy pomocy magicznych pomocników;

3) zasadniczą osobliwością językową jest wyzyskanie w narracji wyrażeń i zwrotów formalistycznych stanowiących podstawę leksykalną gatunku.

\footnotetext{
2 Vide, tamże.

${ }^{3}$ Ibidem, s. 10

4 W.J. P r o p p, Morfologia bajki, „Pamiętnik Literacki” 1968, z. 4.

${ }^{5}$ J. Ł u g o w s k a, Ludowa bajka magiczna jako tworzywo literatury, Wrocław 1981, s. 21.
} 
Rosyjska ludowa bajka magiczna w pełni odpowiada powyższym kryteriom. Reprezentuje ogromną ilość wątków tematycznych - ponad 150, w wielu wypadkach tzw. „wędrownych”, które w zetknięciu z ludową kulturą rosyjską nabierały swoistej barwy, odbijały przyrodę kraju, jego stare obyczaje, jego wierzenia, "ubierały" wydarzenia w rodzimą, oryginalną szatę leksykalną. Jak stwierdza W.I. Kaługin,

почти все былинные и сказочные сюжеты относятся к числу „бродячих", совпадающих в фольклоре разных стран и народов. В узбекских, татарских, сербских, скандинавских, немецких сказках есть свой „колобок”, как в литовских, шведских, испанских своя „репка”, в португальских, турецких, индийских, арабских - своя „Царевна-Лягушка” [...]. Но самое поразительное состоит как раз в том, что „бродячие” образы не привели (podkreślenie nasze, H. W, M. W-K) к стиранию национальных черт, к созданию некого единого для всех стран и народов фольклорного эсперанто 6 .

Za najbardziej popularny wątek uznać można wędrówkę po różnych carstwach - miedzianym, srebrnym i złotym: Три царства - медное, серебряное и золотое ${ }^{7}$. Carstwo morskie zaś jest terenem i miejscem akcji w bајсе Морской иарь и Василиса Премудраяв.

Często powtarzającym się wątkiem jest też historia poszukiwania zaginionego męża lub żony - Цареbна Лягушка, Пёрышко Финиста ясна сокола9.

Ulubionym tematem są również dzieje mądrych i odważnych niewiast - oprócz wymienionych bajek należy tu wskazać bajki Мудрая деbа, Мyдрая девица и семь разбойникоһ, Василий-ијаревич и Елена Прекрасная ${ }^{10}$.

Innym charakterystycznym dla bajki rosyjskiej wyznacznikiem jest fabuła oparta na schemacie: присказка, зачин, повествование, развязка. Wymienione części struktury bajki nacechowane są specyficznymi, częstokroć trudno przetłumaczalnymi zwrotami formulicznymi, przykładowo:

Присказка - rytmizowana, najczęściej nie związana z treścią, a traktowana z ironią wyliczanka, mająca na celu zainteresowanie słuchających:

$$
\begin{aligned}
& \text { Как у наших у ворот } \\
& \text { Муха песенку поет: } \\
& \text { „Что дадите мне за вестку? } \\
& \text { Бьет свекровь свою невестку, }
\end{aligned}
$$

6 Жили-были... Произведения устного народного творчества для детей, состав. и предисл. В.И. Калугина, Москва 1988, s. 12-13.

7 Vide: А.Н. А ф а н а с ь е в, Народные русские сказки в трех томах, Москва 1957, s. $128-132$.

8 Ibidem, s. 219-226.

${ }^{9}$ Ibidem, s. 267-269, 234-235.

10 Ibidem, s. 327-328, 345, 314. Pełny wykaz tytułów sporządzony przez W.J. Proppa znajdziemy w cytowanym wydaniu bajek A.N. Afanasjewa. 


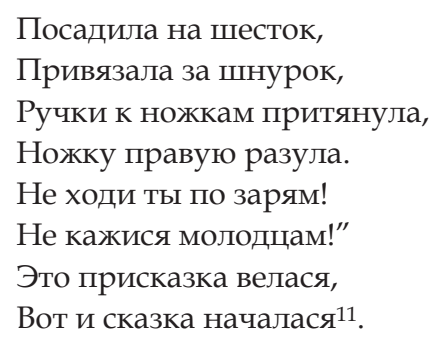

Зачин - krótka inicjalna formuła rozpoczynająca narrację od lokalizacji akcji: „В некотором царстве, в некотором государстве жил...”, „В тридевятом царстве, в тридесятом государстве...”, „В некотором царстве, в некотором государстве, на ровном месте, верст за двести - отсюда не видать".

Повествование - akcja właściwa, w której stosowane są formuły pocieszenia: „не тужи, ложись спать, утро вечера мудренее”; wstawki retardacyjne, „zwalniające” akcję: „скоро сказка сказывается, не скоро дело делается”; oraz inne typowe formułki: „Фу, фу! Прежде русского духу слухом было не слыхать, видом не видать, а нынче русский дух воочию является, в уста бросается и растет герой не по дням, а часам".

Развязка - zakończenie, wyrażone zazwyczaj formułami: „Стали жить-поживать и добра наживать...”, „И я тут был, мед-пиво пил, по устам текло, во рту не было...”, ,"Вот и сказка вся - больше врать нельзя”"12.

Elementem istotnym rosyjskiej bajki magicznej, bez którego fabuła nie mogłaby istnieć i rozwijać się, jest bohater obdarzony nadludzką siłą i umiejętnościami, co znajduje potwierdzenie w przydawkach i epitetach, np. Михайло-богатырь, а ponieważ bajkę tworzył człowiek przygnębiony biedą i pogardzany przez możnych tego świata, odbijały się w niej jego pragnienia i marzenia. I dlatego przysłowiowy Иванушка-дурачок, Емеля-дурак, najmłodszy syn-nieudacznik okazują się najmądrzejsi, najodważniejsi i zdobywają rękę carewny.

Szczególną estymą w bajce magicznej cieszą się postaci kobiece. Wyrazem uznania dla ich urody są przydawki (przydomki) dodawane do imienia: Василиса Прекрасная, ненаглядная красота, красна девица itp. Wyrazem pozytywnego stosunku twórców bajek magicznych do kobiet jest nie tylko uznanie dla ich zewnętrznej urody. Niejednokrotnie w treści bajek napotkać można pochwałę ich zalet ducha, jak wierność, kierowanie się określonymi zasadami, niezależność sądów, wyrażane formułami премудрая, мудрая дева.

11 Teksty z folkloru syberyjskiego wykorzystane przez P. Jerszowa w bajce Koнек-горбунок.

12 Vide: В.П. А н и к и н, Русская народная сказка, Москва 1959. 
Obok bohaterów pozytywnych w magicznej bajce rosyjskiej występują przedstawiciele zdecydowanie negatywni, przy czym są oni w większości przypadków wytworem fantazji rosyjskich twórców folkloru: Кощей Бессмертный, Идолище поганое, Змей Горыныч oraz czarodzieje i czarownice o różnych preferencjach.

W bajkach rosyjskich istnieje też szereg postaci alternatywnie negatywnych. Do tej właśnie grupy należy Баба-Яга Костяная Нога. W większości bajek występuje ona jako wcielenie złych mocy: porywa dzieci, straszy je gorącym piecem itp. Czasem jednak dopomaga bohaterowi w odnalezieniu ukochanej osoby, zaopatrując w cudowne czarodziejskie przedmioty. Zwraca uwagę ich bogactwo i różnorodność: гусли-самогуды, волшебное кольцо, сума, шляпа, рожок, скатерть-самобранка. Wśród „сudownych pomocników" nie brak również istot ożywionych - серый волк, золотая рыбка, сивка-бурка, жар-птица.

Ze stylistyczno-językowego punktu widzenia bajkę magiczną wyróżnia spośród innych gatunków folkloru prozatorskiego fakt pojawienia się w jej leksyce określonych formuł - szczególnie dużej grupy ornamentacyjnych formuł inicjalnych i finalnych, o czym już była mowa, oraz epitetów stałych. Tę właściwość bajki rosyjskiej trafnie określa W. Anikin:

Русская красота и нарядность вошла в языковую „плоть” волшебной сказки. Это не полутона, это глубокие густые цвета, подчеркнуто определенные и резкие. В сказке идет речь о „темной ночи”, о „белом свете”, о „красном солнышке”, о „синем море”, о „белых лебедях", о „черном вороне”, о „зеленых лугах”. Народ воспринял действительность всеми чувствами. Вещи в сказках пахнут, имеют вкус, яркий цвет, отчетливые формы, известен материал, из которого они сделаны. Доспехи на герое „словно жар горят”, вынул, говорит сказка, он свой „острый меч”, натянул „тугой лук”. Дворец в сказках - „белокаменный”, лес - „темный”, „частый”, перстень „золотой”, камни „самоцветные”, камни „острые”, ковер „шелковый” [...]. Народ любит бытие, жизнь, вещи, мир и сумел возвести в поэзию сотни обыденных предметов и вещей. Эти черты свойственны сказке в той же мере, в какой они присущи всему фольклору. Волшебная сказка запечатлена лучшими чертами национального искусства, так как уходит всеми корнями в народную психику, в восприятие, культуру и язык народа ${ }^{13}$.

W kontekście powyższych wypowiedzi słusznym wydaje się stwierdzenie A. Puszkina, iż w magicznej bajce rosyjskiej panuje "russkij duch” i „pachnie Rusią"14. Równocześnie nasuwa się pytanie, w jakim stopniu ową specyfikę ludowej magicznej bajki rosyjskiej potrafiły oddać przekłady polskie.

13 W.P. A n i k i n, op. cit., s. 185-186.

14 А.С. П у ш к и н, Полное собрание сочинений в десяти томах, т. 4: Поэмы и сказки, Москва 1963, s. 11. 
Pierwsze przekłady i adaptacje rosyjskich bajek ludowych zaczęły się ukazywać w latach 1948-1952. Wydano wówczas dwa zbiory Baśni opracowane przez Wandę Markowską i Annę Milską; zbiór baśni narodów ZSRR pod tytułem Złote ręce, zebrany i opracowany przez N. Kołpakową a przełożony przez N. Olszewską; kilka bajek zebranych przez I. Karnauchową, m.in. Najcudowniejsza piękność w przekładzie (a raczej spolszczeniu) Cz. Jastrzębiec-Kozłowskiego ${ }^{15}$. Ponadto w roku 1983 ukazał się wybór bajek pt. Mocarni czarodzieje w przekładzie A. Braczewskiego't6.

Powyższe wybory będą stanowiły materiał badawczy naszej wypowiedzi. Zajmiemy się $w$ pierwszym rzędzie zbadaniem warstwy leksykalno-semantycznej na poziomie imion własnych i towarzyszących im epitetów stałych oraz specyficznych formuł rosyjskich charakteryzujących postaci głównych bohaterów.

Imiona własne są istotnym wyznacznikiem przynależności narodowej, toteż $\mathrm{w}$ większości przekładów nie razi zachowanie oryginalnych rosyjskich imion głównych bohaterów - Iwan, Dymitr, Fiodor, Aleksy, Jemiela, jak również popularnych imion żeńskich - Wasylisa, Jelena, Maria Moriewna czy Nastazja Warchamiejówna ${ }^{17}$, podobnie jak naturalnym wydaje się $\mathrm{w}$ przekładach $\mathrm{z}$ angielskiego zachowanie oryginalnych Huck Finn, Mowgli, Mary Poppins. W tym kontekście nie rażą również deminutywa rosyjskie typu Iwanuszka ${ }^{18}$.

Nie zawsze jednak tłumacze decydują się na przeniesienie imion rosyjskich do przekładu polskiego. Dotyczy to szczególnie imienia Iwan, odbieranego $\mathrm{w}$ środowisku polskim jako przezwisko (w rodzaju szwab, fryc w odniesieniu do Niemców). Zastępowano je więc Janem, Jasiem, a nawet Iwasiem. Narusza to w pewnym sensie koloryt utworu, ale wydaje się możliwe do przyjęcia ze względu na podobieństwo leksykalno-fonetyczne. Całkowicie natomiast nieuzasadnione wydaje się przemianowanie Fiodora na Teodora czy tak mocno w bajce rosyjskiej osadzonej Wasylisy na Klarysę. ${ }^{19}$

Przejdźmy teraz do przeanalizowania wybranych epitetów przyimiennych. Na ogół podobieństwo językowe sprzyja ekwiwalencji, a więc Елена Прекрасная występuje w przekładzie jako Jeliena Prześliczna²0, i choć można

15 Vide: Bibliografia literatury dla dzieci 1945-1960. Przekłady, Warszawa 1971, poz. 6-9, $382 ; 377,381 ; 648$.

16 Mocarni czarodzieje, baśnie rosyjskie, wybór, przekład, posłowie, przypisy A. Bratoszewski, Warszawa 1983.

17 Vide: Baśnie różnych ludów, oprac. W. Markowska i A. Milska, Warszawa 1948; Mocarni czarodzieje..., op. cit.

18 I. K a r n a u c h o w a, Najcudowniejsza piękność, spolszczył Cz. Jastrzębiec-Kozłowski, Warszawa 1951, s. 114-120.

19 O Iwaszce-głuptasku, [w:] Baśnie narodów Zwiazku Radzieckiego, zebrały i oprac. W. Markowska i A. Milska, Warszawa 1950, s. 14.

20 Vide: Mocarni czarodzieje..., op. cit., s. 102. 
by, pozostając $\mathrm{w}$ tej samej konwencji, zaproponować przepiękna czy nawet nadobna, to jednak częściej spotykamy epitet przymiotnikowy piękna21.

Oryginalny rosyjski przymiotnik ненаглядная, występujący w tytule zbioru bajek I. Karnauchowej22, tłumacz oddaje jako najcudowniejsza (piękność), natomiast u J. Tuwima spotykamy kalkę językową nienapatrzona, co brzmi jak neologizm i jest na gruncie polskim semantycznie dwuznaczne - czy chodzi o urodę, na którą nie można się nigdy dostatecznie napatrzyć, czy też o urodę zapatrzoną samą w siebie, narcystycznąa23. Stąd wydaje się, iż przekład Cz. Jastrzębiec-Kozłowskiego jest funkcjonalnie adekwatny do treści bajki.

Niewątpliwą trudność sprawia tłumaczom oddanie przymiotnika-przydawki Премудрая. Słowo to zawiera w sobie pole semantyczne o wiele szersze niż mądra24, zaś dosłowne gramatycznie tłumaczenie (kalkowanie) na wzór przepiękna jako przemądra nasuwa niekorzystne, wręcz negatywne asocjacje z polskim odpowiednikiem leksykalno-gramatycznym przemądrzała.

Poważne zastrzeżenia mogą budzić translacje tytułów Царевна-лягушка i Финист-Ясный сокол. Otóż we wspomnianym zbiorze Najcudowniejsza piękność 25 pierwszy z tytułów brzmi Królewna-Żabusia. Nie znajdujemy żadnego uzasadnienia (prócz osobistych tendencji "spolszczeniowych") dla użycia w bajce rosyjskiej słowa królewna, królestwo - czyli leksyki niezgodnej z faktycznym stanem ustrojowym Rosji carskiej, tym bardziej że istnieje precedens w tłumaczeniach uprzednich słów: car, carewicz, carówna ${ }^{26}$. Jeszcze bardziej razi słowo Żabusia, wywołujące niesmaczne i zupełnie nieadekwatne skojarzenie emocjonalne z tytułową bohaterką znanej sztuki G. Zapolskiej.

Dostojeństwem i powagą owiana jest opowieść o wierności i odwadze bohaterki, która wyrusza w świat na poszukiwania ukochanego Finista nie Sokolika, a właśnie Sokoła Jasnego, ukochanego męża, dlatego nieadekwatnym emocjonalnie wydaje się imię bohatera w tłumaczeniu polskim - "sfrancuziałe” Ludwik. O wiele bardziej trafną wydaje się propozycja A. Barszczewskiego - Finist Sokót Promienisty 27.

21 Ibidem, s. 43.

22 Ibidem.

23 Vide: B. Ł a z a r c z y k, Sztuka translatorska Juliana Tuwima, Wrocław-WarszawaKraków-Gdańsk 1979, s. 66.

24 Vide: Król morski i Helena Mądra, [w:] I. K a r n a u c h o w a, Najcudowniejsza piękność..., op. cit, s. 76.

25 Ibidem, s. 46.

26 Vide m.in. Mocarni czarodzieje..., op. cit.

27 Ibidem, s. 74. 
Przedstawiliśmy jedynie wybrane problemy i trudności piętrzące się na drodze tłumacza rosyjskiej magicznej bajki ludowej. Nie sposób bowiem $\mathrm{w}$ ramach krótkiego artykułu omówić zasadzki związane z ekwiwalencją licznych epitetów emocjonalnych i przedmiotowych oraz bogactwa porzekadeł i formuł czasowo-przestrzennych. Powinny one stać się przedmiotem obszernego i wszechstronnego studium. 